Verver, D., Merten, H., Robben, P., Wagner, C. Care and support for older adults in The Netherlands living independently. Health and Social Care in the Community: 2018, 26(3), e404-
e414

\begin{tabular}{|l|l|}
$\begin{array}{l}\text { Postprint } \\
\text { Version }\end{array}$ & 1.0 \\
\hline Journal website & http://onlinelibrary.wiley.com/doi/10.1111/hsc.12539/full \\
\hline Pubmed link & $\underline{\text { https://www.ncbi.nlm.nih.gov/pubmed/29377470 }}$ \\
\hline DOI & $10.1111 / \mathrm{hsc} .12539$ \\
\hline
\end{tabular}

This is a NIVEL certified Post Print, more info at http://www.nivel.eu

\title{
Care and support for older adults in The Netherlands living independently
}

\author{
Didi VerVer MSC ${ }^{1}$, HANNEKe MERTEN PhD CANDIDATE ${ }^{2}$, PAUl RobBen PHD ${ }^{3,4}$, \\ CORDULA WAGNER PHD ${ }^{5,6}$ \\ ${ }^{1}$ Department of Public and Occupational Health, Amsterdam Public Health Research \\ Institute, VU University Medical Center, Amsterdam, The Netherlands \\ ${ }^{2}$ Department of Public and Occupational Health, Amsterdam Public Health Research \\ Institute, VU University Medical Center, Amsterdam, The Netherlands \\ ${ }^{3}$ Dutch Healthcare Inspectorate (IGZ), Utrecht, The Netherlands Institute of Health Policy \\ and Management (iBMG), Erasmus Universiteit Rotterdam, Rotterdam, The Netherlands \\ ${ }^{4}$ Department of Public and Occupational Health, Amsterdam Public Health Research \\ Institute, VU University Medical Center, Amsterdam, The Netherlands \\ ${ }^{5}$ The Netherlands Institute for Health Services Research (NIVEL), Utrecht, The Netherlands
}

\begin{abstract}
The growth in the numbers of older adults needing long-term care has resulted in rising costs which have forced the Dutch government to change its long-term care system. Now, the local authorities have greater responsibility for supporting older adults and in prolonging independent living with increased support provided by the social network. However, it is unclear whether these older adults have such a network to rely upon. The objective of this study was to gain insight into the providers of formal and informal care to older adults, and to assess possible differences between older adults who are frail and those who are not. In addition, we investigated their care and support needs. We used data from a quantitative survey using a cross-sectional design in different regions of the Netherlands from July until September $2014(n=181)$. Frailty was measured using the Tilburg Frailty indicator. To analyse the data chi-square tests, crosstabs and odds ratios were used for dichotomous data and the MannWhitney $U$-Test for nominal data. The number of formal care providers involved was significantly higher $($ median $=2)$ for those deemed frail than for those not deemed frail (median $=1$ ), $U=2,130, p<.005$. However, more than one-third of the respondents deemed frail did not get the care or support they needed $(33.7 \%)$. There was a significant positive association between being frail and having an informal care provider $\left(\chi^{2}=18.78, d f=1, p<.005\right)$. However, more than one-third of those deemed frail did not have an informal care provider (36.8\%). One-third of older adults deemed to be frail did not have their needs sufficiently addressed by their care network. For a substantial part of this group
\end{abstract}


Verver, D., Merten, H., Robben, P., Wagner, C. Care and support for older adults in The Netherlands living independently. Health and Social Care in the Community: 2018, 26(3), e404e414

of older adults, the informal network seems to be unable to support them sufficiently. Additional attention for their needs and wishes is required to implement the policy reforms successfully.

\section{What is known about this topic}

- The increasing population of older adults makes it necessary to look for solutions to fulfil their care and support needs; Independent living, selfsufficiency and reliance on a social network are becoming increasingly important; When there are more health impairments, the number of formal care providers increases.

\section{What this paper adds}

- An overview of the number and type of formal and informal care providers involved in the care network around independently living older adults; Frailty is associated with having an informal care provider, however, one-third of the respondents considered to be frail, did not have an informal care provider; One-third of the respondents considered to be frail reported that they did not receive all the care and support they needed, implying that the informal care network was not always able to fulfil these needs.

\section{INTRODUCTION}

\subsection{The long-term care system and policy assumptions}

According to the European Commission and the European Union's advisory body 'the Social Protection Committee' (2014), long-term care is defined as "a range of services and assistance for people who, as a result of mental and/or physical frailty and/or disability over an extended period of time, depend on help with daily living activities and/or are in need of some permanent nursing care". There are differences in arrangements for long-term care between different member states of the European Union, especially in the relative weight assigned to formal and informal care. In general, the family is mainly responsible for long-term care in Southern and Eastern European countries. In Northern European countries, the state traditionally has an important role in the organisation and payment of long-term care. The amount of money spent on long-term care also varies accordingly. In 2010, the Netherlands had the highest total percentages of recipients of long-term care and the highest density of carers per 1,000 population (nearly 19 carers per 1,000 population). Because of the costs accompanied with this, and the expansion of the population of older adults needing long-term care, the Dutch government was forced to change their care system. Since January 1, 2015 the Exceptional Medical Expenses Act (AWBZ) was replaced. It is now only possible for people in the Netherlands to be admitted to a care institution if they need intensive care and supervision day and night. This is covered by the new "wet langdurige zorg" (Wlz), which, translated, means the longterm care Act. Other aspects of long-term care, such as support and welfare delivered at home, have been transferred to the "wet maatschappelijke ondersteuning" (Wmo) which, translated, means Social Support Act, whose provisions are the responsibility of the local authorities. Medical care is still covered by the "Zorgverzekeringswet" (Zvw), which, translated, means the Dutch Health Insurance Act. The objective is to enhance self-sufficiency and prolong independent living as long as possible (ageing at home). This also applies to older adults and other vulnerable groups of people 
Verver, D., Merten, H., Robben, P., Wagner, C. Care and support for older adults in The Netherlands living independently. Health and Social Care in the Community: 2018, 26(3), e404-
e414

(Dutch House of Parliament, 2013). Consequently, more people with long-term complex problems will continue to live independently in the years to come. In an attempt to offset the rising demand for care, the Dutch government, in addition to promoting self-sufficiency, is attempting to promote an increased role for the social network of frail older adults as a source of long-term care (Dutch House of Parliament, 2013). Other developed countries also face similar challenges. According to the European Commission and the European Union's (EU) advisory body the Social Protection Committee (2014), the vast majority of older adults in all EU countries prefer to maintain "independent living" as long as possible. As such, integration of long-term care with other services is seen as an important challenge. Informal care providers within a social network will often have a shared history with the care recipient. This will offer greater knowledge of the values and preferences of the older adult than formal care providers have. In this way, informal care can be more responsive than formal care (Keating, Otfinowski, Wenger, Fast, \& Derksen, 2003). However, receiving care and/or support from within a social network may not be viable for every older adult. Different factors such as marriage, parenthood and other intimate ties play a role in the composition of social support networks (Rausa, 2008). Therefore, it is important to have a clear understanding of the characteristics and potential of these adults living independently and their social network, before assuming these policy assumptions are actually feasible.

\subsection{Frailty}

One important aspect to consider is that the proportion of frail older adults living independently has risen (Clegg, Young, Iliffe, Rikkert, \& Rockwood, 2013; Van Campen, 2011). Frailty can be described as an accumulation of physical, psychological and/or social problems, which enhances the risk of negative health outcomes such as functional decline, institutionalisation or death (Van Campen, 2011). However, although frailty is a widely discussed subject, there is still no definition which is accepted internationally. Frail older adults often experience multiple conditions and diseases and consequently use multiple care providers (Béland et al., 2006). Frail older adults seem to have less local social capital. They know fewer people in their neighbourhood whom they can ask for help, compared to older adults who are not frail (Vermeij, 2016). Because of possible problems in multiple areas and their smaller social capital, frail older adults tend to be at risk when they live independently. The focus of the government on self-sufficiency and the support network may therefore be asking too much of this particular group. In this study, we speak of older adults living independently when they live alone, with their spouse or other relatives. When they live in a sheltered accommodation or housing designed for older people with on-call staff, it was not defined as independent living.

\subsection{Informal and formal care}

The Dutch government believes that an important function of the social network is to provide informal care and support instead of, or in addition to, formal care. Informal care is unpaid care delivered by someone in the social network of the older adult. The definition of an informal care provider by the Ministry of Health, Welfare and Sport (VWS) is: long-term care for those in need, by people in their direct social network and on the basis of a social relationship, and not provided on a professional basis (VWS 2001). It is known that informal care networks of older adults living 
Verver, D., Merten, H., Robben, P., Wagner, C. Care and support for older adults in The Netherlands living independently. Health and Social Care in the Community: 2018, 26(3), e404e414

independently on average are small, and the carers are usually female, dominated by family or relatives, mostly young to middle-aged, and live in households separate from the care recipient. For many older adults, the informal care network consists of a sole female carer (Broese van Groenou, Jacobs, Zwart-Olde, \& Deeg, 2016; Keating et al., 2003).

Research has also shown that networks of people with long-term health problems are different in composition, size and sustainability from those of older adults without such problems (Wenger, 1997). It is suggested that the presence of sustainable networks may function as a buffer against the effects of failing health and increasing frailty. Wenger (1991) states that support networks of frail older adults have higher proportions of close family and relations and are smaller than those without chronic health problems. This may imply that those who are in most need of care, may be least likely to have a robust support network, especially if they have little contact with their children or when they do not have any children.

In an ideal situation, formal and informal care providers form a care network around the adult living independently. According to a longitudinal study by Geerlings, Margriet Pot, Twisk, and Deeg (2005), the use of formal care usually follows on from the use of informal care and is based on a person's particular health problem and/or the loss of care from a spouse or partner. The number of formal care providers involved also increases when health problems are more serious (Li, 2005). According to Suanet, van Groenou, and Van Tilburg (2012), in Europe an average of only 17\% of the older adults who receive care, receive this from both informal and formal care providers. This number varies widely across countries. In the Czech Republic, it is $3 \%$; in the Netherlands, it is $22 \%$. However, this number is likely to increase in Europe and in other developed countries since independent living and care and support from the social network is desirable (Da Roit, 2012; Suanet et al., 2012).

\subsection{Care networks}

Currently, there is little empirical evidence about the composition and functioning of care networks. However, the structure of care networks is considered to be important for understanding how they function (Carpentier \& Ducharme, 2003). Research concerning the number and type of care providers involved, their tasks, and the interactions between the individual care providers, seems to be in its infancy (Broese van Groenou et al., 2016; Carpentier \& Ducharme, 2003).

Although care networks are an important topic for policy and research, there is no accepted international definition. One definition of a network is "a more or less stable pattern of social relations among different actors (people, groups, organisations) who depend on each other to reach their goals without the existence of a dominant actor. Network relations imply that co-ordination among actors takes place on the basis of mutual benefit, reciprocity and trust" (van Wijngaarden, de Bont, \& Huijsman, 2006).

\subsection{The aim and the research question}

Although it is clear that care networks, and the role of informal care, are important for older adults to continue to live independently, little is known about their composition, activities and sustainability. Insight into this is desirable, given the increasing number of older adults with complex problems living independently, combined with the focus of policy on the independence and self-reliance of frail people. This could provide information to analyse whether these assumptions are 
Verver, D., Merten, H., Robben, P., Wagner, C. Care and support for older adults in The Netherlands living independently. Health and Social Care in the Community: 2018, 26(3), e404-
e414

feasible for frail older adults living independently in the community and if these care networks can fulfil their needs. As a first step in this process, an answer to the following research questions was sought in this study: Which care providers, formal and informal, are involved in the care and support for older adults living independently? Are older adults living independently in need of more care or support than they receive? If yes, does this need for more care and support differ between older adults who are frail and those who are not frail?

\section{METHODS}

\subsection{Design and setting}

This article describes a cross-sectional quantitative study. A questionnaire was sent to 582 older adults living independently and covered topics about health, frailty, the involvement of care providers, help or support in their social network and the need for care and support. It was developed through qualitative interviews with older adults living independent during a previous phase of a larger study (Verver et al., 2015). The complete study examined the care networks of these older adults and how to regulate them. It consisted of four phases: a risk analysis using literature; a pilot study; a survey study and an evaluation of a new regulation framework. Data for the current article were gathered during phase III, the survey study. The complete study was funded by the Netherlands Organisation for Health Research and Development (ZonMw). The study was embedded within the Academic Collaborative Centre on Supervision (AWT) established in 2011. Here, four different research institutions work together over a four-year period with the Dutch Healthcare Inspectorate (IGZ), in order to develop evidence-based supervision.

The study was approved by the Scientific Committee of the EMGO+ Institute and the medical ethical review committee of the VU University Medical Centre. Participants had to sign an informed consent form to participate in the study. All information gathered about the participants was used only for this study and was processed separately from participant identifiers in order to protect their privacy and confidentiality.

\subsection{Recruitment and sampling}

During the pilot study, different organisations involved in the care or welfare of older adults living independently were approached by telephone. These included: homecare organisations; service flats; housing co-operatives; volunteer and welfare organisations and general practitioners. They were asked to participate in selecting those considered frail among their group for a qualitative face-to-face interview (Verver et al., 2015). In addition, the organisations were asked to participate in the current phase of the project and to send the questionnaires to adults of 75 years and older who lived independently. A general practitioner in a city in the eastern region of the Netherlands, a volunteer organisation in the city of Amsterdam and a housing co-operative in a rural area in the province of North Holland also agreed to participate in this phase. The variety in the types of organisations was needed in order to collect information from older adults with different backgrounds and to have a varying intensity in the care offered by the organisations. The inclusion criteria given to the three organisations were simply that the participants needed to be 75 years or older and living independently. No exclusion criteria were set. The organisations sent the questionnaires to everyone who fitted those criteria, with the 
Verver, D., Merten, H., Robben, P., Wagner, C. Care and support for older adults in The Netherlands living independently. Health and Social Care in the Community: 2018, 26(3), e404-
e414

exception of the housing co-operative which selected, at random, 200 older adults out of a total of approximately 1,500. The organisations sent the questionnaire together with an informed consent form, information sheet and return envelope by mail to the older adults in order to respect their privacy. The outcomes were processed separately from the participant identifiers.

\subsection{Data collection}

In July 2014, 582 questionnaires were sent to older adults living independently. These comprised 237 from the general practitioner, 145 from the volunteer organisation and 200 from the housing co-operative. Older adults, who participated, filled in the questionnaire and sent it directly to the researchers by mail using the return envelope included.

\subsection{Materials}

There were different components of the questionnaire which were used for this manuscript. First, the Tilburg Frailty Indicator (TFI), based on the conceptual model of frailty by Gobbens, van Assen, Luijkx, Wijnen-Sponselee, and Schols (2010) was used to identify those who deemed frail. It consists of 15 items covering different areas of frailty; physical, social and psychological (Gobbens et al., 2010). All positive scores on an item were summarised to calculate a total score for frailty. A total score of five or higher was used as a cut-off point for frailty (Cronbach's Alpha $=0.73)($ Gobbens \& van Assen, 2012; Gobbens et al., 2010).

\subsubsection{Formal network}

The number of formal care providers involved with the individual's care was asked using a systematically arranged figure. The question was: "Did you have contact with one or more of the following care providers?" The respondents could mark the care provider or providers with whom they had contact in the past year. The following options were given: medical specialists, with open space to specify the function; personal care provider; paid domestic help; nurse or home-care nurse; psychologist; day-care services; physiotherapist; social worker; community centre; welfare organisation and other, with open space for text. The general practitioner and the dentist were not taken into account, since the involvement of a general practitioner and dentist is more or less self-evident for inhabitants of the Netherlands.

\subsubsection{Informal care provider}

Information about the potential involvement of informal care providers was also collected within the systematically arranged figure which was used in the questionnaire to assess the formal care network. The options for the relationship with the informal care provider given in the table were: partner; child or children; sibling; neighbour; other, with open space for text.

\subsubsection{Type of support and the need for care and support}

We asked whether the respondents received help or support from their children, since not all help/support is seen as informal care. When they answered "yes", they were then asked to fill out an open question about the tasks their children performed. The same type of questions were asked about the need for care/support and social contacts. 
Verver, D., Merten, H., Robben, P., Wagner, C. Care and support for older adults in The Netherlands living independently. Health and Social Care in the Community: 2018, 26(3), e404-
e414

\subsection{Analysis}

IBM SPSS software 22.0 (SPSS Inc., Chicago, IL, USA) was used to analyse the data. Frequencies and descriptive statistics were used to display background characteristics and to explore the data. The analysis for frail older adults compared to those who are not frail in relation to the presence of an informal care provider was performed with a chi-square test. A $p$-value of .05 or lower was seen as statistically significant. The size of the formal network is a nominal scale (0-11) without a normal distribution. After a log transformation, the distribution was still skewed to the right. Therefore, a Mann-Whitney $U$-Test was used to analyse differences in the total number of formal providers involved with the care of frail older adults and those who are not frail. Crosstabs and odds ratios were used to analyse differences between the two sets of older adults with regard to their needs for more care/support and social contacts.

\section{RESULTS}

\subsection{Response rate}

A total of 181 questionnaires were filled out by the respondents $(31.1 \%)$. The number of questionnaires received from older adults approached by the general practitioner was $94(51.9 \%)$, the housing co-operative $59(32.6 \%)$ and the volunteer organisation $28(15.5 \%)$.

\subsection{Information about people who did not participate}

1. In addition to the 181 respondents, 95 people returned an empty questionnaire of whom 69 wrote down their reason for not participating: 23 were not willing or interested in participating.

2. 18 respondents did not consider the questionnaire applicable to them as they did not receive any care at that moment and they lived independently.

3. Nine respondents wrote that the burden of the questionnaire was too high.

4. Five participated in other research and did not want to participate in another study.

5. Five had died.

6. Four said that they were not able to answer the questions. These included those suffering from dementia.

7. Three did not want to participate because of privacy considerations.

8. Two did not feel they met the criteria.

\subsection{Description of the characteristics of the respondents}

The mean age of the respondents was 81.5 years $(S D=4.99)$. Divided up among the different organisations, the mean age for the GPs' respondents was 80.9 years $(S D=4.98)$, for the housing co-operatives' respondents was 81.46 years $(S D=4.72)$ and for the volunteers organisations' respondents was 83.68 years $(S D=5.22)$. More than half of the respondents were female $(58.6 \%)$. Almost half of the respondents lived alone (49.2\%), 39.2\% were widowed and $87.8 \%$ had one or more children. According to the Tilburg Frailty Indicator, 95 (52.5\%) respondents were frail. Table 1 shows the characteristics of the respondents. 
Verver, D., Merten, H., Robben, P., Wagner, C. Care and support for older adults in The Netherlands living independently. Health and Social Care in the Community: 2018, 26(3), e404-
e414

\section{[TABLE 1]}

\subsection{The presence of an informal care provider and the relationship with the older adult}

Information about informal care providers was missing for four respondents $(2.2 \%)$. In total, $81(47 \%)$ respondents had one or more informal care providers. Frail older adults had an informal care provider significantly more often than respondents who were not frail $\left(58.9 \%\right.$ versus $\left.29.1 \%, \chi^{2}=18.78, d f=1, p<.005\right)$.

The child or children $(n=46)$, and partner $(n=24)$, were the types of informal care providers mentioned most often.

Children were the most frequent informal care provider $(n=31)$ within the subgroup of widowed respondents. In cases where the respondents were married, the partner $(n=20)$ was more often mentioned as an informal carer than the children $(n=6)$. Table 2 shows the persons reported to be involved in the informal care network for the total group of respondents and different subgroups.

\section{[TABLE 2]}

\subsection{Types of tasks provided by children (not shown in the table)}

Eighty-two respondents $(45.3 \%)$ indicated that they received help or support from their children, though it does not necessarily mean that the child is mentioned by the older adult as an informal care provider. In total, they mentioned 106 different tasks their children helped them with. Among those mentioned most often were: buying groceries and sorting out finances ( $n=22$ respondents); taking out the rubbish $(n=7)$; cleaning up the house $(n=7)$; transportation $(n=7)$; chores $(n=6)$; garden $(n=5)$; electronics $(n=5)$; administration $(n=5)$ and doctors' appointments $(n=5)$.

\subsection{Support by other people in the social network (not shown in the table)}

Forty-two of all the respondents (23.2\%) had other people in their social network who helped or supported them with daily chores. This is in addition to the informal care provider already mentioned. Most often mentioned were the neighbours $(n=9)$ and the paid domestic help $(n=8)$. Of the frail respondents $(n=95) 28$ had another person who provided informal care/support in addition to their informal care provider. For those who were not frail $(n=86)$, this number was $14(\mathrm{OR}=2.1 ; 95 \%$ $\mathrm{CI}=1.03-4.39)$.

\subsection{Presence of formal care providers and their occupation}

The median formal care network for all the respondents consisted of two (IQR $=2$; Range $=0-11$ ) care providers, excluding the general practitioner and dentist. In total, 44 respondents $(24.3 \%)$ had no formal care providers. The median formal care network for the frail respondents consisted of two (IQR $=3$; Range $=0-11)$ care providers, and for respondents who were not frail it was one (IQR $=2$; Range $=0-5$ ). This difference is significant $U=2,130, p<.005$.

The types of formal care providers most often present in the care networks for all respondents, not taking into account the general practitioner and the dentist, were: paid domestic help $n=67$ (37\%); ophthalmologist $n=39$ (21.5\%); physiotherapist $n=39(21.5 \%)$; cardiologist $n=29(16 \%)$ and personal care provider $n=29(16 \%)$. Table 3 gives an overview of the type of care providers involved in the formal care of the respondents. It also includes a separate overview for respondents who were 
Verver, D., Merten, H., Robben, P., Wagner, C. Care and support for older adults in The Netherlands living independently. Health and Social Care in the Community: 2018, 26(3), e404e414

frail and those who were not frail. One single respondent could mention multiple care providers.

\section{[TABLE 3]}

\subsection{Need for care or support}

In total, 34 respondents (18.8\%) indicated they were in need of more care and support than they received at the time of the questionnaire. Of the 34 respondents who were in need of more care or support, 30 specified one or more needs. Extra care or support with domestic help was most often mentioned by this group (table 4). Of these 34 respondents, 32 were frail which means that $33.7 \%$ of the frail respondents $(n=95)$ were in need for more care or support and $2.3 \%$ of the respondents who were not frail $(n=86)(\mathrm{OR}=21.42$; CI 95\% $=4.95-92.78)$. Of the frail respondents who were in need of more care or support $(n=32), 11$ had an informal care provider, 19 did not and, for two respondents, this was unknown. Of the frail respondents who were not in need of more care or support $(n=62), 36$ had an informal care provider, 24 did not and, for two respondents, this was unknown. See Figure 1 for the graphic display of this information.

\section{[TABLE 4][FIGURE 1.]}

Thirty-seven $(20.4 \%)$ respondents were in need of more social contacts. Of these respondents, 32 were frail, which means that $33.7 \%$ of the frail respondents $(n=95)$ were in need of more social contacts and $5.8 \%$ of the respondents who were not frail $(\mathrm{OR}=8.13$; CI 95\% $=2.99-22.06)$. A total of 27 respondents specified their need for social contact. More company or social contacts and activities were mentioned most often (table 4).Within the group of respondents with an informal care provider $(n=81), 19$ were in need of more social contacts. For respondents without an informal care provider $(n=96)$, this number was $16(\mathrm{OR}=1.51 ; 95 \% \mathrm{CI}=0.72$ 3.18).

\section{DISCUSSION}

\subsection{Interpretation of the findings}

The results of this study show that many different types of formal care providers are involved in the care and support of older adults living independently. The paid domestic help was the one most often involved, without taking the general practitioner and dentist into account. The care providers involved in the networks of those older adults living independently are different and specific for every situation. Of all the respondents, $18.8 \%(n=34)$ were in need of more care or support. Almost all of these respondents were frail which means that one-third of the frail older adults were in need of more care or support while there were hardly any respondents in need of more care or support in the non-frail group.

The results also show that having an informal care provider does not automatically imply that these needs can be met, since one-third of the frail older adults in need of more care or support did have an informal care provider. Furthermore, although the frail older adults are involved with more formal care providers, and more often with an informal care provider, they are, however, often in need of more care or support. In other words, the frail older adults may have received more care and support than 
Verver, D., Merten, H., Robben, P., Wagner, C. Care and support for older adults in The Netherlands living independently. Health and Social Care in the Community: 2018, 26(3), e404-
e414

older adults who were not frail, but one-third of the frail older adults is still in need of more.

It is assumed that, at the local level, local authorities would be more capable of addressing the needs and wishes of people living independently. They should, it is assumed, be better able to organise the care and support needed (Dutch Houses of Parliament 2013, 2014). If the care and support needs of frail older adults are to be met sufficiently, then insight into their circumstances is important.

A recent study in the Netherlands showed that family ties and the capacity of families to offer care, cannot always be assumed. Furthermore, provision of care or support could put additional pressure on the family relationship (Vermeij, 2016). These results contribute to the conclusion that individual factors are important for older adults living independently in relation to their ability to rely on their social network when in need of more care or support. Besides putting pressure on the relationship with the family, informal care also puts pressure on, and burdens upon, the carer (Carretero, Garcés, Ródenas, \& Sanjosé, 2009). The impact which the provision of care has on informal care providers is not reduced by introducing instrumental help. In addition, instrumental help is often delivered without an evaluation of the informal care providers' needs (Carretero, Garcés, \& Ródenas, 2007).

A study by Bonsang (2009) states that informal care can be a substitute for long-term care as long as the needs of the older adults are low, require unskilled care, and not too many commitments. This may explain the need for more care and support for the frail older adults in this study who already have an informal care provider. Informal carers may not be able to provide the care and support needed because this may be too intensive. The inability of informal care providers to deliver more intensive care is important if any future policy, relying on informal care, is designed to decrease long-term care expenditures, since this may adversely impact on a proportion of the frail older adults. Policy makers need to decide whether the drop in expenditure in the long run is more important than providing tailored care, and in particular professional care, to older adults who live independently.

Another important factor when considering the increased role of the social network is the reluctance of older adults to ask them for help. This was also established in a study in the United States which showed that older adults do not want to bother relatives or other people in their social network. Older adults feel that these people are already busy with their jobs and their own lives, and taking care of an older relative may be a severe burden on them (Cahill, Lewis, Barg, \& Bogner, 2009). This reluctance may prohibit the realisation of informal care even though these frail older adults may be in need of more care, support and social contacts. The findings of this study suggest that the assumptions in policies that older people could be more independent, self-reliant and involved in a social network, may be partly feasible for older adults living independently. The question is whether the frail older adults are capable of creating a sustainable care and support network. Future research should bear this in mind when investigating the transition to long-term care and its consequences.

\subsection{Strengths and limitations}

The total response rate in the current study was satisfactory when taking into account the population and information regarding the people who did not participate. This is because older adults and the severely ill may experience a greater response burden, 
Verver, D., Merten, H., Robben, P., Wagner, C. Care and support for older adults in The Netherlands living independently. Health and Social Care in the Community: 2018, 26(3), e404-
e414

and therefore more often do not respond (Stone, Shiffman, Atienza, \& Nebeling, 2007). Also, data were collected in different regions in the Netherlands to make the data more generally applicable. Information about the composition of the care network for informal as well as formal care providers is fairly new and therefore provides important information about older adults living independently and their care providers.

Despite the effort to collect data which can be applied across the board, the sample is quite small and severely frail older adults may not have been able to fill out the questionnaire. Also, ethnic minorities and other minority groups are underrepresented in this study. This should be taken into account when interpreting the data.

The response rates for the different organisations varied from $15.5 \%$ to $51.9 \%$. The causes of these differences were not investigated, but may be partly explained by the extent to which the different organisations were involved with the care of older adults. A general practitioner is, in general, more involved with his patients than a housing co-operative with its clients. Older adults may be closely involved with their direct volunteers but perhaps less with the organisation behind these volunteers. In this study, we did not collect data about the intensity of contact and the total hours of contact and support. This could have provided more information about the functioning of a care network. However, this option was considered when composing the questionnaire, but we decided not to take this into account because of doubts about the ability of older adults to recall this information. The requirement to recall and collect these data would certainly have imposed a serious burden on the respondents and this could have led to a lower response rate.

Another possible limitation was the use of the term "informal care provider". As this is a commonly used term in the Netherlands, it was left up to the older adults to decide whether to mark someone as an informal care provider or not without using formal definitions. This could have led to information bias, where some older adults who received a considerable amount of help from their children did not perceive this as "informal care". Vice versa, children who provide groceries, maybe once a week, and perform no other care tasks could be designated as an informal care provider by the older adults. This would be the case for both the frail older adults and those who were not. Therefore, we do not expect this to influence the differences between both groups.

Finally, the older adults were asked in the questionnaire to check, in a table, whether they had contact with the specified care providers in the last year. This table was quite extensive and this could have led to some missing data. Even though it was an extensive table and questionnaire, it would have been desirable to have a more complete description by seeking additional information about the intensity of the care and support received, and, for example, the support based on technology.

\subsection{The conclusions and implications for practice, policy and further research}

The changes made in long-term care underline the importance for older adults living independently of receiving support and care from a social network. The results of this study suggest that the policy which is focused on self-sufficiency and the support network may be feasible for most older adults living independently. However, onethird of the frail older adults did not receive all the care and support they needed, even though most already had an informal care provider. 
Verver, D., Merten, H., Robben, P., Wagner, C. Care and support for older adults in The Netherlands living independently. Health and Social Care in the Community: 2018, 26(3), e404-

These results mean that it cannot be assumed that frail older adults are able to nivel continue to be independent through an increasing reliance upon their social support network. Additional attention to their needs and wishes, and an assessment of the situation of frail older adults and their social support network, are required to implement the policy reforms successfully.

\section{ACKNOWLEDGEMENTS}

We thank everyone who contributed to the organisation of the data collection as well as the older adults and their care providers who participated in the interviews.

\section{CONFLICT OF INTEREST}

The researchers declare they do not have any competing interests.

\section{AUTHOR CONTRIBUTION}

D. Verver has written the manuscript and analysed the data. H. Merten was involved in the execution of the study and has critically reviewed this manuscript. P. Robben critically reviewed this manuscript. C. Wagner obtained research funding, was involved in the design of the study and critically revised the manuscript for important intellectual content. All authors read and approved the final manuscript.

\section{Funding information}

This work was supported by the Netherlands Organization for Health Research and Development (ZonMw) [grant number 80-83505-98-004].

The study is embedded in the "academic collaborative centre on supervision" (AWTDutch acronym) in 2011. Here, four different research institutions work together with the IGZ during a 4-year period in order to develop evidence-based supervision. The current study is executed by the EMGO+ Institute/VU medical centre in close collaboration with the IGZ, in order to link research and practice.

\section{REFERENCES}

Van Campen, C. (2011) Frail older adults [Original title in Dutch: Kwetsbare Ouderen]. The Hague, the Netherlands: Dutch Institute for Social Research (SCP).

Vermeij, L. (2016). Small gestures, the importance of villagers for older adults on the countryside [Original title in Dutch: Kleine gebaren. Het belang van dorpsgenoten voor ouderen op het platteland]. The Hague, the Netherlands: Dutch Institute for Social Research (SCP).

Wenger, G. C. (1991). A network typology: From theory to practice. Journal of Aging Studies, 5(2), 147-162. https://doi.org/10.1016/0890-4065(91)90003-B

Wenger, G. C. (1997). Review of findings on support networks of older Europeans. Journal of Cross-Cultural Gerontology, 12(1), 1-21. https:// doi.org/10.1023/A:1006597110040 van Wijngaarden, J. D., de Bont, A. A., \& Huijsman, R. (2006). Learning to cross boundaries: The integration of a health network to deliver seamless care. Health Policy, 79(2), 203213. https://doi.org/10.1016/j.healthpol.2006.01.002

Verver, D., Merten, H. A., Robben, P. A., \& Wager, C. (2015). Supervision of care networks for frail community dwelling older adults aged 75 years and older: protocol of a mixed methods study. BMJ open, 5(8), e008632.

Béland, F., Bergman, H., Lebel, P., Clarfield, A. M., Tousignant, P., Contandriopoulos, A.-P., \& Dallaire, L. (2006). A system of integrated care for older persons with disabilities in Canada: Results from a randomized controlled trial. The Journals of Gerontology Series A: Biological Sciences and Medical Sciences, 61(4), 367-373. https://doi.org/10.1093/ gerona/61.4.367 
Verver, D., Merten, H., Robben, P., Wagner, C. Care and support for older adults in The Netherlands living independently. Health and Social Care in the Community: 2018, 26(3), e404-

Bonsang, E. (2009). Does informal care from children to their older parents substitute for formal care in Europe? Journal of Health Economics, 28, 143-154. https://doi.org/10.1016/j.jhealeco.2008.09.002

Broese van Groenou, M., Jacobs, M., Zwart-Olde, I., \& Deeg, D. J. (2016). Mixed care networks of community-dwelling older adults with physical health impairments in the Netherlands. Health \& Social Care in the Community, 24(1), 95-104. https://doi.org/10.1111/hsc. 12199

Cahill, E., Lewis, L. M., Barg, F. K., \& Bogner, H. R. (2009). "You Don't Want to Burden Them" older adults' views on family involvement in care. Journal of Family Nursing, 15(3), 295-317. https://doi.org/10.1177/1074840709337247

Carpentier, N., \& Ducharme, F. (2003). Care-giver network transformations: The need for an integrated perspective. Ageing and Society, 23(04), 507-525. https://doi.org/10.1017/S0144686X03001211

Carretero, S., Garcés, J., \& Ródenas, F. (2007). Evaluation of the home help service and its impact on the informal caregiver's burden of dependent elders. International Journal of Geriatric Psychiatry, 22, 738-749. https:// doi.org/10.1002/(ISSN)1099-1166

Carretero, S., Garcés, J., Ródenas, F., \& Sanjosé, V. (2009). The informal caregiver's burden of dependent people: Theory and empirical review. Archives of Gerontology and Geriatrics, 49(1), 74-79. https://doi.org/10.1016/j.archger.2008.05.004

Clegg, A., Young, J., Iliffe, S., Rikkert, M. O., \& Rockwood, K. (2013). Frailty in elderly people. Lancet, 381, 752-762. https://doi.org/10.1016/ S0140-6736(12)62167-9

Da Roit, B. (2012). The Netherlands: The struggle between universalism and cost containment. Health \& Social Care in the Community, 20(3), 228-237. https://doi.org/10.1111/j.1365-2524.2011.01050.x Dutch House of Parliament (2013, April 25). Parliamentary papers II 2012- 2013, 30597. no. 296. p.2. The Hague.

Dutch House of Parliament (2014, January 1). Parliamentary Papers II 2013-2014, 30597. no. 280, 2014, p. 1. The Hague Dutch Ministry of Health, Welfare and Sports (2001). 'Care nearby'. Memorandum about the informal care provider. The Hague, Ministry of VWS [original title in Dutch: Zorg nabij, notitie over mantelzorg ondersteuning] European Commission and Social Protection Committee (2014). Adequate social protection for longterm care needs in an ageing society. Luxembourg: Publications Office of the European Union. European Union. ISBN 978-92-79-39282-5 - https://doi.org/10.2767/32147

Geerlings, S. W., Margriet Pot, A., Twisk, J. W., \& Deeg, D. J. (2005). Predicting transitions in the use of informal and professional care by older adults. Ageing and Society, 25(1), 111-130. https://doi.org/10.1017/S0144686X04002740

Gobbens, R., \& van Assen, M. (2012). De Tilburg Frailty Indicator: Validiteit en betrouwbaarheid. Tijdschrift voor Ouderen-geneeskunde, 37(2), 75-79.

Gobbens, R. J., van Assen, M. A., Luijkx, K. G., Wijnen-Sponselee, M. T., \& Schols, J. M. (2010). The Tilburg frailty indicator: Psychometric properties. Journal of the American Medical Directors Association, 11(5), 344- 355. https://doi.org/10.1016/j.jamda.2009.11.003

Keating, N., Otfinowski, P., Wenger, C., Fast, J., \& Derksen, L. (2003). Understanding the caring capacity of informal networks of frail seniors: A case for care networks. Ageing and Society, 23(01), 115-127. https:// doi.org/10.1017/S0144686X02008954

$\mathrm{Li}, \mathrm{L}$. W. (2005). Longitudinal changes in the amount of informal care among publicly paid home care recipients. The Gerontologist, 45(4), 465-473. https://doi.org/10.1093/geront/45.4.465

Rausa, B. A. (2008). Social support. In S. Loue \& M. Sajatovic (Eds.), Encyclopedia of ageing and public health (pp. 751-754). Boston, MA: Springer Science \& Business Media. https://doi.org/10.1007/978- 0-387-33754-8 410

Stone, A., Shiffman, S., Atienza, A., \& Nebeling, L. (2007). The science of real-time data capture. New York, NY: Oxford University Press.

Suanet, B., van Groenou, M. B., \& Van Tilburg, T. (2012). Informal and formal home-care use among older adults in Europe: Can cross-national differences be explained by societal context and composition? Ageing and Society, 32(03), 491-515. https://doi.org/10.1017/ S0144686X11000390 
Verver, D., Merten, H., Robben, P., Wagner, C. Care and support for older adults in The

Netherlands living independently. Health and Social Care in the Community: 2018, 26(3), e404-
e414

TABLES

Table 1. The background characteristics of the respondents

\begin{tabular}{|c|c|c|c|}
\hline Characteristic & Categories & \begin{tabular}{|c|} 
Mean $(S D)$ or \\
Frequency $(\%)$ \\
\end{tabular} & $\begin{array}{l}\text { Number of } \\
\text { missing } \\
\text { answers (\%) }\end{array}$ \\
\hline $\begin{array}{l}\text { Age in years (mean, } \\
S D)\end{array}$ & & $81.50(5)$ & $12(6.6)$ \\
\hline \multirow{2}{*}{$\begin{array}{l}\text { Gender, frequency } \\
(\%)\end{array}$} & Men & 71 (39.2) & \multirow{2}{*}{$4(2.2)$} \\
\hline & Women & $106(58.6)$ & \\
\hline \multirow{2}{*}{$\begin{array}{l}\text { Country of birth, } \\
\text { frequency (\%) }\end{array}$} & The Netherlands & $164(90.6)$ & \multirow{2}{*}{$5(2.8)$} \\
\hline & Other & $12(6.6)$ & \\
\hline \multirow{3}{*}{$\begin{array}{l}\text { Living situation } \\
\text { (frequency }(\%) \text { ) }\end{array}$} & Independent, alone & 89 (49.2) & \multirow{3}{*}{6 (3.3.) } \\
\hline & Independent, with partner & $71(39.2)$ & \\
\hline & Other & $15(8.3)$ & \\
\hline \multirow{4}{*}{$\begin{array}{l}\text { Marital status, } \\
\text { frequency (\%) }\end{array}$} & Married & 72 (39.8) & \multirow{4}{*}{$4(2.2)$} \\
\hline & Widowed & $71(39.2)$ & \\
\hline & Divorced & 19 (10.5) & \\
\hline & Other & $15(8.3)$ & \\
\hline \multirow{2}{*}{$\begin{array}{l}\text { Children, frequency } \\
(\%)\end{array}$} & Yes & $159(87.8)$ & $3(1.7)$ \\
\hline & No & $19(10.5)$ & \\
\hline $\begin{array}{l}\text { Frailty, mean score } \\
(S D)\end{array}$ & & $5.1(3.4)$ & \\
\hline \multirow{2}{*}{$\begin{array}{l}\text { Frail }(\mathrm{TFI} \geq 5), \\
\text { frequency }(\%)\end{array}$} & Yes & $95(52.5)$ & \\
\hline & No & 86 (47.5) & \\
\hline \multirow{7}{*}{$\begin{array}{l}\text { Educational level, } \\
\text { frequency (\%) }\end{array}$} & $<6$ years of primary school & $7(3.9)$ & \multirow{7}{*}{$12(6.6)$} \\
\hline & \begin{tabular}{|l}
6 years of primary school, (special \\
education)
\end{tabular} & $16(8.8)$ & \\
\hline & $\begin{array}{l}\text { More than primary school/primary } \\
\text { school without completed follow- } \\
\text { up education }\end{array}$ & $22(12.2)$ & \\
\hline & \begin{tabular}{|c|} 
Diploma for follow-up education, \\
but less than vocational school \\
\end{tabular} & $30(16.6)$ & \\
\hline & Vocational school & $58(32.0)$ & \\
\hline & Secondary professional education & $19(10.5)$ & \\
\hline & University entrance level & $17(9.4)$ & \\
\hline \multirow{7}{*}{$\begin{array}{l}\text { Monthly income, } \\
\text { frequency (\%) }\end{array}$} & Less than $€ 1,250$ & $31(17.1)$ & $7(3.9)$ \\
\hline & Between $€ 1,250$ and $€ 1,750$ & $50(27.6)$ & \\
\hline & Between $€ 1,750$ and $€ 2,300$ & $32(17.7)$ & \\
\hline & Between $€ 2,300$ and $€ 2,900$ & $15(8.3)$ & \\
\hline & Between $€ 2,900$ and $€ 3,500$ & $13(7.2)$ & \\
\hline & Higher than $€ 3,500$ & $11(6.1)$ & \\
\hline & No answer/do not know & $22(12.2)$ & \\
\hline
\end{tabular}

Table 2. The different types of respondents and the presence and type of informal care provider involved 


\begin{tabular}{|c|c|c|c|c|c|c|}
\hline $\begin{array}{l}\text { Persons reported } \\
\text { to be involved in } \\
\text { the informal } \\
\text { care network }\end{array}$ & $\begin{array}{l}\text { For the total } \\
\text { group of } \\
\text { respondent } \\
\text { s, } n=181, \\
\text { frequency } \\
\%) \text { a }\end{array}$ & \begin{tabular}{|l|} 
For \\
respondents \\
who \\
reported to \\
have an \\
informal \\
care \\
provider, \\
$n=81$, \\
frequency \\
$(\%)$ a \\
\end{tabular} & \begin{tabular}{|l|} 
\\
For frail \\
respondents, \\
$n=95$, \\
frequency \\
(\%)a
\end{tabular} & \begin{tabular}{|l|} 
For \\
responde \\
nts who \\
are not \\
frail, \\
$n=86$, \\
frequency \\
$(\%) a$
\end{tabular} & \begin{tabular}{|} 
For widowed \\
respondent \\
s, $n=71$ \\
frequency \\
(\%)a
\end{tabular} & \begin{tabular}{|l} 
For married \\
respondent \\
s, $n=72$, \\
frequency \\
(\%)a
\end{tabular} \\
\hline \multicolumn{7}{|c|}{ a The percentages shown are based on the number of the respondents within the subgroup. } \\
\hline \begin{tabular}{|l|l|} 
Partner \\
\end{tabular} & $24(13.3)$ & $24(29.6)$ & $12(12.6)$ & $12(14)$ & $2(2.8)$ & $20(27.8)$ \\
\hline Child(ren) & $46(25.5)$ & $46(56.8)$ & $34(35.8)$ & $12(14)$ & $31(43.7)$ & $6(8.3)$ \\
\hline Sibling & $6(3.3)$ & $6(7.4)$ & $4(4.2)$ & $2(2.3)$ & $3(4.2)$ & 0 \\
\hline Neighbour & $17(9.4)$ & $17(21.0)$ & $11(11.6)$ & $6(7.0)$ & $10(14.1)$ & $4(5.6)$ \\
\hline Other & $16(8.8)$ & 16 (19.8) & 14 (14.7) & $2(2.3)$ & $8(11.3)$ & 0 \\
\hline None & $96(53)$ & 0 & 35 (36.8) & $61(70.9)$ & $31(43.7)$ & 46 (63.9) \\
\hline Missing & $44(2.2)$ & 0 & $4(4.2)$ & 0 & 0 & $2(2.8)$ \\
\hline
\end{tabular}

Table 3. The number of older adults who had contact with the following care provider in the past year

\begin{tabular}{|c|c|c|c|}
\hline $\begin{array}{l}\text { Professional care } \\
\text { provider }\end{array}$ & \begin{tabular}{|l|} 
All respondents \\
$(n=181)$, frequency \\
$(\%) \mathrm{a}$
\end{tabular} & $\begin{array}{l}\text { Frail respondents } \\
(n=95), \text { frequency } \\
(\%) \text { a }\end{array}$ & $\begin{array}{l}\text { Respondents who were } \\
\text { not frail }(n=86) \\
\text { frequency }(\%) \text { a }\end{array}$ \\
\hline \multicolumn{4}{|c|}{ a Multiple professional care providers could be indicated by one respondent. } \\
\hline Paid domestic help & $67(37.0)$ & $53(55.8)$ & $14(16.3)$ \\
\hline Ophthalmologist & $39(21.5)$ & $26(27.4)$ & $13(15.1)$ \\
\hline Physiotherapist & $39(21.5)$ & $30(31.6)$ & $9(10.5)$ \\
\hline Cardiologist & $29(16.1)$ & $18(18.9)$ & $11(12.8)$ \\
\hline Personal care provider & $29(16.0)$ & $23(24.1)$ & $6(7.0)$ \\
\hline $\begin{array}{l}\text { Medical specialist, } \\
\text { other }\end{array}$ & $23(12.7)$ & $13(13.7)$ & $10(11.6)$ \\
\hline Orthopaedist & $15(8.3)$ & $14(14.7)$ & $1(1.2)$ \\
\hline Internist & $13(7.2)$ & $8(8.4)$ & $5(5.8)$ \\
\hline Nurse & $11(6.1)$ & $9(9.5)$ & $2(2.3)$ \\
\hline Neurologist & $11(6.1)$ & $7(7.4)$ & $4(4.7)$ \\
\hline Other & $11(6.1)$ & $9(9.5)$ & $2(2.3)$ \\
\hline Psychologist & $10(5.5)$ & $9(9.5)$ & $11(1.2)$ \\
\hline Urologist & $9(5.0)$ & $5(5.3)$ & $4(4.7)$ \\
\hline Pulmonologist & $8(4.4)$ & $5(5.3)$ & $3(3.5)$ \\
\hline Dermatologist & $7(3.9)$ & $2(2.1)$ & $5(5.8)$ \\
\hline Otorhinolaryngologist & $6(3.3)$ & $4(4.2)$ & $2(2.3)$ \\
\hline Day care & $5(2.8)$ & $3(3.2)$ & $2(2.3)$ \\
\hline Social worker & $5(2.8)$ & $5(5.3)$ & 0 \\
\hline Gastroenterologist & $4(2.2)$ & $2(2.1)$ & $2(2.3)$ \\
\hline Rheumatologist & $4(2.2)$ & $2(2.1)$ & $2(2.3)$ \\
\hline
\end{tabular}


Verver, D., Merten, H., Robben, P., Wagner, C. Care and support for older adults in The Netherlands living independently. Health and Social Care in the Community: 2018, 26(3), e404e414

\begin{tabular}{||l||l|l|l||}
\hline $\begin{array}{l}\text { Professional care } \\
\text { provider }\end{array}$ & $\begin{array}{l}\text { All respondents } \\
(\boldsymbol{n}=\mathbf{1 8 1}), \text { frequency } \\
(\%) \mathbf{a}\end{array}$ & $\begin{array}{l}\text { Frail respondents } \\
(\boldsymbol{n}=\mathbf{9 5 )}, \text { frequency } \\
(\%) \mathbf{a}\end{array}$ & $\begin{array}{l}\text { Respondents who were } \\
\text { not frail }(\boldsymbol{n}=\mathbf{8 6}), \\
\text { frequency }(\%) \mathbf{a}\end{array}$ \\
\hline \hline Geriatrician & $3(1.7)$ & $1(1.1)$ & $2(2.3)$ \\
\hline Neurosurgeon & $2(1.1)$ & $2(2.1)$ & 0 \\
\hline \hline Anaesthesiologist & $2(1.1)$ & $1(1.1)$ & $1(1.2)$ \\
\hline \hline Community centre & $2(1.1)$ & $1(1.1)$ & $1(1.2)$ \\
\hline Welfare organisation & $2(1.1)$ & $1(1.1)$ & 0 \\
\hline \hline Gynaecologist & $1(0.6)$ & $1(1.1)$ & 89 \\
\hline Total & 290 & 201 & $1.2)$ \\
\hline
\end{tabular}

Table 4. Type of needs on care/support and social contacts, presented in numbers

\begin{tabular}{|c|c|}
\hline \begin{tabular}{|l|} 
Type of need for more care or \\
support
\end{tabular} & $\begin{array}{l}\text { Mentioned by } 30 \text { of the } 34 \text { respondents who wanted } \\
\text { more care/supporta }\end{array}$ \\
\hline \begin{tabular}{|l|} 
Paid domestic help (more or \\
new)
\end{tabular} & 些 \\
\hline Social aspects & 7 \\
\hline Help with buying groceries & 3 \\
\hline Financial help & 1 \\
\hline Help with transport & 2 \\
\hline Less care or domestic care & 1 \\
\hline Less pain & 1 \\
\hline Help to go outside & 1 \\
\hline Day care for the very old & 1 \\
\hline More loving care & 1 \\
\hline $\begin{array}{l}\text { Type of need for more social } \\
\text { contacts }\end{array}$ & $\begin{array}{l}\text { Mentioned by } 27 \text { of the } 37 \text { respondents who wanted } \\
\text { more social contactsa }\end{array}$ \\
\hline \multicolumn{2}{|c|}{ a More than one need could be specified by the respondent. } \\
\hline Company/contacts & 14 \\
\hline Activities (right level) & 10 \\
\hline More/closer contact with family & 3 \\
\hline $\begin{array}{l}\text { Contact where another person } \\
\text { takes the initiative }\end{array}$ & $\mid 1$ \\
\hline
\end{tabular}


Verver, D., Merten, H., Robben, P., Wagner, C. Care and support for older adults in The

Netherlands living independently. Health and Social Care in the Community: 2018, 26(3), e404e414

Figure1 The number of frail respondents split by need for more care/support and the presence of an informal care provider

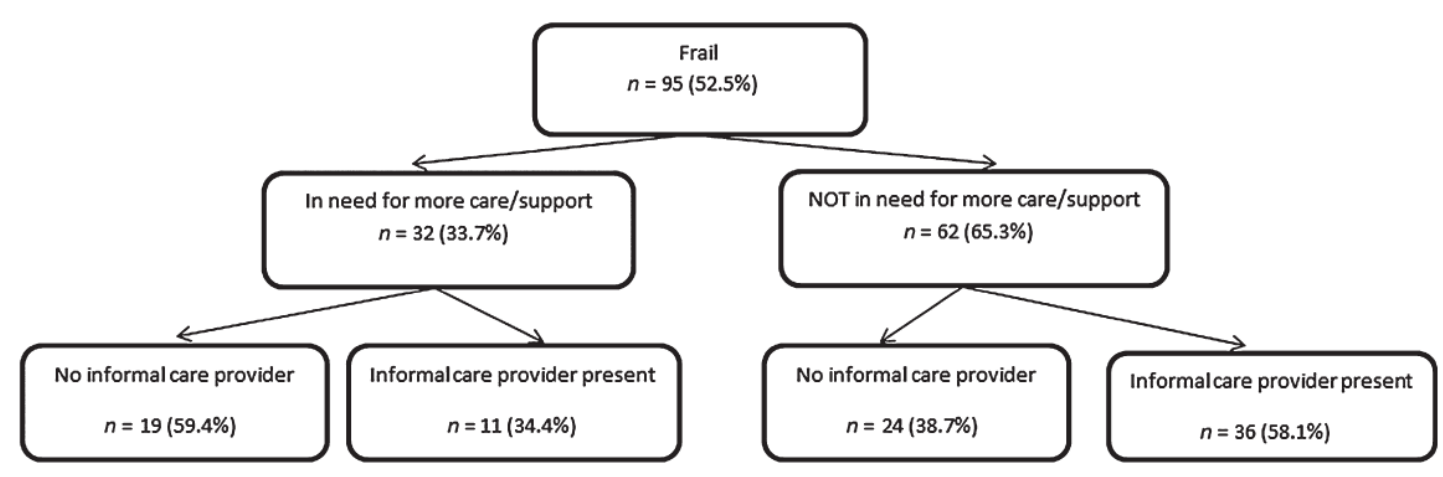

